paring boys for their studies, it may be hoped that a more general union may be arrived at with regard to this standard.

Free libraries are still progressing, and so interesting are the statistics of these "universities of the people" in the United States, that Gen. Eaton promises a special publication on the subject, reprinting such parts of the great Report of 1877 as have permanent value. Several magnificent bequests and donations of books to large libraries show how naturally large private collections will gravitate to the free public library, where the locality is happily provided with onc. One such, that of Dr. Toner's, containing 27,000 books and 12,000 pamphlets, was thus bequeathed to the Library of Congress. This latter institution, at the end of 1882 , already contained 480,076 volumes and 160,000 pamphlets, and the forthcoming plan of a new building to keep in utilising order this rapidly growing mass is intended to embody the best appliances, arrangements, and ideas about library construction which such enormous accumulations render indispensable. An excellent precaution also against knowledge being locked up in over-large supplies of literature is taken at Chicago, where Dr. Poole, the great cataloguist, receives schools or teachers on a Saturday, surrounded by all the books of the library bearing upon some matter. By showing how interesting that subject is as a department of human thought and industry, and how much the contents of the library may help the student to a knowledge of such a subject, he has succeeded in producing a profound beneficial effect upon the upper grades of the school system. W. ODELI

\section{BIRDS BREEDING IN ANTS' NESTS}

TIIE following communication to $\mathrm{Mr}$. Grant Duff, Governor of Madras, has been forwarded to us for publication by Sir John Lubbock:-

\section{To Major Awdry, Private Secretary to His Excellency the Governor of Madras}

$$
\text { OOTY, January 18, I885 }
$$
date.

SiR,-I beg to acknowledge your letter of yesterday's

The Southern Chestnut Woodpecker (Micropternus gularis), always, as far as I have observed, uses an ants nest to nest in, and Mr. Gammie, the Superintendent of the Government Cinchona Estates at Mongphoo, near Darjeeling, has noticed the same thing with regard to the allied northern species, Microptemus phaloceps, and the peculiarity probably extends also to the allied specics found in Burmah, Siam, \&c.

Mr. Gammie thinks that when an ants' nest has been taken possession of by the bird that the ants descrt the nest. This is a point on which I cannot speak with certainty. Mr. Gammie has taken nests of the northern species in which, although the bird had laid, the ants remained, and he has taken other nests where not a single ant remained; but there is nothing to show that these nests were not deserted before the bird took possession. I myself have taken nests of the southern form, in which, though the eggs were partially incubated, the ants remained, showing that some considerable time must have clapsed since the bird tools possession. This is at point that I hope to be able to elucidate within the next few months, when the birds will be breeding.

When Micropternus is breeding the feathers of the head, tail, and primaries of the wings get covered with a viscid matter, having a strong resinous smell, and this substance is usually rather thickly studded with dead ants (wille "Stray Feathers," vol. vi. p. 145).

Two species of kingfishers also to my knowledge nidi ficate in ants' nests-viz. Malcyon occipitalis, confined to the Nicobar Islands, and H. chloris, which ranges from India as far south as Sumatra.
At Mergui, in South Tenasserim, I found a nest of $H I$. chloris in a hornets' nest, and although I saw the birds repeatedly enter the hole they had made in the hornets' nest the hornets did not seem to mind it, but they resented in a very decided manner my attempt to interfere with the nest.

I am sorry I cannot give His Excellency more certain information as regards the desertion or otherwise of the ants from their nest after the birds have taken possession of it, but I hope to be able to finally settle the question shortly.

$$
\begin{aligned}
& \text { I am, Sir, yours obediently, } \\
& \text { (Signed) WM. DAvison }
\end{aligned}
$$

\section{A NEW AMERICAN CLOCK}

$T \mathrm{HE}$ accompanying figure from $L a$ Nature illustrates a new $\Lambda$ merican clock of ingenious construction. It is distinguished from all other clocks by the singular and original form of its pendulum : or rather of the system which serves to maintain a synchronism more or less perfect between the passage of time and the indications on the dial. The arrangement of this clock is based on

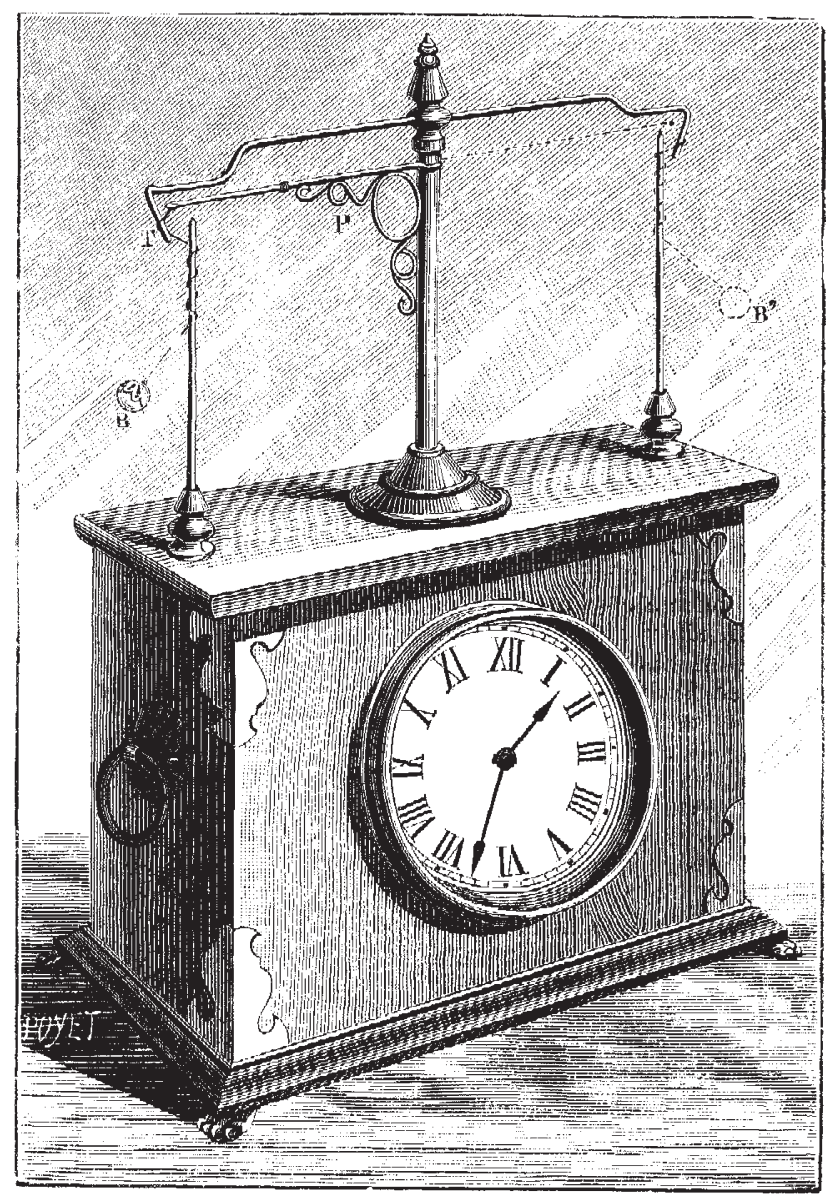

the principle of torsion. It has to be wound up daily, and the phase of the pendulum - that is to say, the time which elapses between two identical positions of the regulating system -is six seconds. The general mechanism does not differ from that of ordinary clocks; we find the main spring and other usual parts, and a train of wheels giving rotation to a vcrtical axis which is seen over the case and the rate of motion of which is to be regulated. 
Here the new mechanism comes in. This vertical axis supports a sort of bracket, $\mathrm{P}$, to the extremity of which is attached a small bead or ball, $\mathrm{B}$, by means of a thread a few centimetres long. Putting out of view meantime the other parts resting on the case, it will be seen that the axis, by the action of the main spring, will turn with a rapid movement, drawing the ball $\mathrm{B}$ along with it. To regulate this movement, it is sought to interpose in its path suitable obstacles; this is the object of the horizontal wire terminating in the hooks $\mathrm{T}$, and of the vertical pillars fixed on the case. The bracket $P$ draws the thread in its movement and makes it strike against the arm ' $\mathrm{T}$; it is thus arrested, and by virtue of its acquired speed, the ball B winds the thread around the pillar on the left; then follows an unwinding of the thread and a rewinding in an inverse direction, which enables the thread to pass the point $T$. But in unwinding it strikes a second time against the pillar, winds and unwinds anew, and only

\section{A CLOUD-GLOW APPARATUS}

$\mathrm{B}^{\mathrm{y}}$ the kindness of Prof. J. Kiessling, of Hamburg, we illustrate a simple and easily arranged piece of apparatus which he has designed for the purpose of exhibiting on an experimental scale some of the many colour-phenomena which are produced when direct sunlight, or electric light, penetrates a moist or a dry cloud. In particular the apparatus can be used to produce on an artificially excited mist the same kinds of intense colorations which were visible in such extraordinary brilliancy in the winter $1883^{-84}$ during the hours of twilight at almost every place the whole world over.

The following pieces compose the apparatus:-

I. A glass globe, A, Fig. I, holding about 20 litres, fixed succeeds in passing this double obstacle after four successive windings, twice in one direction, and twice in the opposite direction around the same pillar. The thread thus set at liberty permits the bracket to turn $\mathrm{I} 80^{\circ}$ around the vertical axis. After this rotation it encounters two analogous objects placed on the right of the clock, and is delayed a certain time before passing these objects and returning to the pillar on the right. By suitably varying the length of the thread, which is easily done by means of a runner on the bracket, we obtain the complete phase of the movement with its eight successive windings of the thread, lasting exactly six seconds; and the clock is thus regulated, if not with all the precision of a chronometer, with an approximation said to be sufficient for ordinary use. The principle applied in this clock might possibly be utilised in cases where it is sought to regulate a slow movement of rotation by simple arrangements, both economical and uncumbrous.

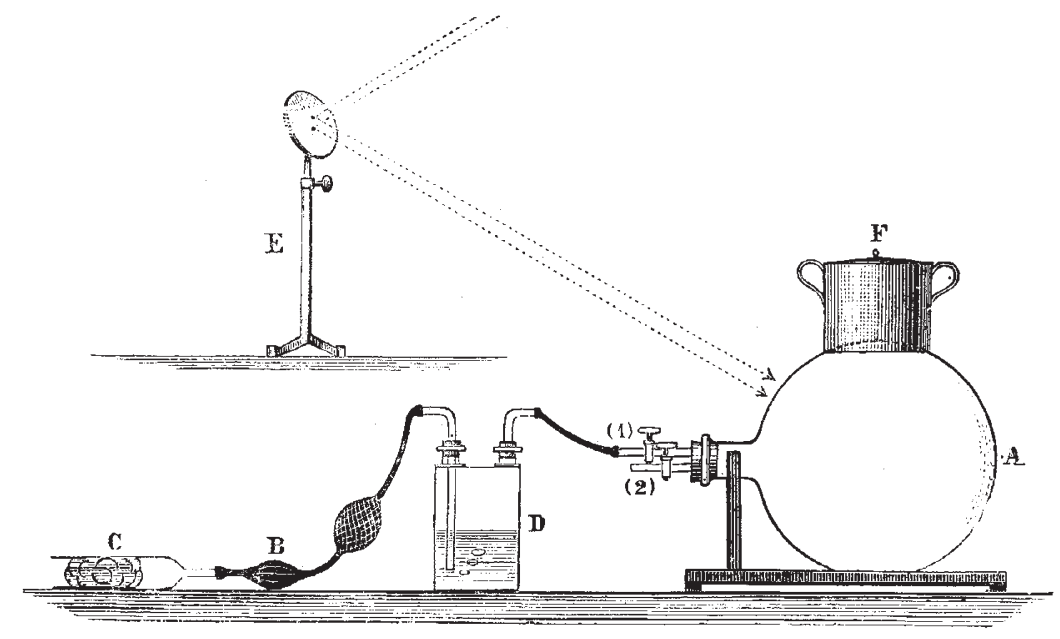

lowering of the temperature, and the production of a tolerably homogeneous mist, the density of which will depend on the quantity of aqueous vapour present.

4. A simple heliostat, $E$, consisting of a mirror capable of being turned either in altitude or azimuth on an iron stand, and also of being clamped at any desired height.

5. A Woulff's wash-bottle, D. This can be filled with hot water so as to yield a supersaturated atmosphere ; or, by the addition of ammonia or of hydrochloric acid, may furnish vapours of these materials for experiment in the globe.

6. A cylindrical tin-ware vessel, $\mathrm{F}$, with a spherical bottom, to be set upon the glass globe, to heat or cool it as may be desired.

The following experiments may be made with this apparatus :- in a wooden support, and closed by a rubber stopper bored with two holes. Through these holes enter two tubes of glass (I) and (2), with taps ground in.

2. An air-filter, $\mathrm{C}$, consisting of a glass tube 30 centimetres long, filled with cotton-wool.

3. An india-rubber pump, $\mathrm{B}$, for producing spray or mist. This is simply part of a common spray-apparatus, and is set so that it draws air from the air-filter and delivers it into the globe. By this means a pressure of one-sixth to one-fifth of an atmosphere is readily obtained. Suppose 15 or 20 grammes of water to have been introduced into the globe and such a pressure to have been produced, and then after about IO-I 5 seconds the other tap (2) to be suddenly opened, or removed quite out of the tube, the release of pressure will result in a sudden

[I] The Ordinary Lunar Halo. First cover the surface of the mirror with a card disk having a central circular opening 2 centimetres in diameter, covered with tissue paper. In direct sunlight observe the bright surface of this circle of tissue paper (which serves as an artificial moon) through the mist that is produced in the globe by letting in a stream of moist vapour from a flask of hot water for a few seconds. The halo is yellowish with a red-brown edge.

[2] Blue Sun. Pour in to the globe a little hydrochloric acid, and blow in air through the wash-bottle, having filled the latter first with liquid ammonia. A dust-cloud of fine particles of sal-ammoniac is thereby produced. A ray of direct sunlight viewed through this is curiously coloured, appearing at the first moment red, and then changing to bluish violet and to full blue. 